\title{
Towards an affordable magnetomyography instrumentation and low model complexity approach for labour imminency prediction using a novel multiresolution analysis
}

\author{
Ejay Nsugbe ${ }^{1}$ and Ibrahim Sanusi ${ }^{2}$ \\ ${ }^{1}$ Affiliation not available \\ ${ }^{2}$ Alten UK
}

February 9, 2021

\begin{abstract}
The ability to predict the onset of labour is seen to be an important tool in a clinical setting. Magnetomyography has shown promise in the area of labour imminency prediction, but its clinical application remains limited due to high resource consumption associated with its broad number of channels. In this study, five electrode channels, which account for $3.3 \%$ of the total, are used alongside a novel signal decomposition algorithm and low complexity classifiers (logistic regression and linear-SVM) to classify between labour imminency due within $0-48 \mathrm{hrs}$ and $>48 \mathrm{hrs}$. The results suggest that the parsimonious representation comprising of five electrode channels and novel signal decomposition method alongside the candidate classifiers could allow for greater affordability and hence clinical viability of the magnetomyography-based prediction model, which carries a good degree of model interpretability.
\end{abstract}

\section{Hosted file}

MMG_Thrsh_Paper_Final.pdf available at https://authorea.com/users/394787/articles/508140towards-an-affordable-magnetomyography-instrumentation-and-low-model-complexityapproach-for-labour-imminency-prediction-using-a-novel-multiresolution-analysis 